\title{
ROLE OF PROPERTY MANAGEMENT IN SERVICE DEMANDS OF ELDERLY RESIDENTS OF APARTMENT COMPLEXES
}

\author{
Ying-Hua HUANG (D) ${ }^{*}$, Pei-Chen LEE \\ Department of Civil and Construction Engineering, National Yunlin University of Science and Technology, \\ Yunlin, Taiwan
}

Received 09 January 2019; accepted 01 July 2019

\begin{abstract}
An aging population results in an increased demand for services designed to meet the needs of elderly people. To enable elderly individuals to age successfully in their original residence environments, property management companies that provide services to apartment complex residents play an important role as service providers. The purpose of this study was to identify possible services that property management companies can provide to elderly residents of apartment complexes in response to changing demographics. Factor analysis was performed to identify the main areas of service demands or service demand aspects. Cluster analysis and a chi-square test were also used to identify and highlight the varied demographic characteristics and residence conditions of respondents and how they affect the level of importance attributed to each service demand aspect. Results showed seven main service aspects that were of concern to elderly individuals. Specific characteristics of elderly people that led to higher demands for certain other service aspects were also identified. The results of this study can serve as a reference for property management companies to help them provide custom design services for apartment complexes they serve and to expand their business scope and opportunities.
\end{abstract}

Keywords: elderly, property management, service demand, aging in place, demand segmentation, supportive services.

\section{Introduction}

Technological and medical advances have led to a decline in human mortality rates and an increase in life expectancy. According to the World Health Organization (WHO), a country with more than $7 \%$ of the total population aged 65 and over is considered to be an aging society; at $14 \%$, it is called an aged society; and at $20 \%$, it is referred to as a super-aged society. On the basis of a 2018-2065 population projection by the National Development Council (2018) in Taiwan, the proportion of the elderly population to the total population in Taiwan is expected to reach $14 \%$ in 2018 and exceed $20 \%$ in 2026. This projected period of eight years for Taiwan to move from an aged society to a super-aged society is shorter than that for Japan (11 years), the United States (14 years), France (29 years), and the United Kingdom (51 years) and is almost the same as that for Korea (8 years) and Singapore (7 years). Because of rapid social changes and the continual increase in the elderly population, issues related to aging are attracting considerable attention and discussion in industries related to housing, health care, social care, employment, economic security, transportation, and leisure for elderly people.
Because of the increased effects of aging on the population structure, countries worldwide are implementing various policies for elderly people, and a key area of focus is known as "aging in place." Because of an increased demand for services related to care of elderly people, policies in Taiwan tend to focus on the concept of "community care" with an emphasis on "aging in place," "home-based care," and "community-based care." This concept allows elderly people to live at homes, stay in the community, and live a healthy, dignified life in a familiar environment. In addition, this concept enhances their sense of belonging to the community and adds value to their lives. The government is committed to driving policies related to public transportation, health care, long-term care, and other services in order to build a suitable environment for aging in place. At the same time, it also creates business opportunities for the property management industry as well as help them implement corporate social responsibilities.

Property management refers to the management of all relevant businesses of a building. The scope of property management companies includes three main sectors: (i) management and maintenance of buildings and the environment, (ii) support services for life and business

*Corresponding author. E-mail: huangyh@yuntech.edu.tw 
activities, and (iii) asset management (Council for Economic Planning and Development, 2004). For residential buildings, such as apartment complexes, property management companies manage and maintain the physical building and living environment and provide a full range of services and operations so that residents living in apartment complexes they serve can have a safe, healthy, convenient, and comfortable home environment. When elderly people represent a large portion of the population, it not only presents a challenge for property management companies to provide important services but also creates a tremendous business opportunity. Property and building management contracts are completed by selective tenders, which maintain a balance of quality control and competitive pricing, both of which are essential for long-run sustainability and growth. According to a survey conducted in Taiwan, approximately 39 of every 100 homes have family members aged 65 or over (Ministry of the Interior, 2015). Changes in the population structure of an apartment complex due to an increase in the number of older adults living there means that the property management company needs to provide different services so that elderly people can have leisure and entertainment as well as enhance their relationships with their neighbors in the apartment complex. The various types of elderly care services provided by a property management company not only increase a company's competitiveness but also assist older adults in successfully aging in place.

In practice, there is currently a gap between services provided by property management companies and the demands of elderly residents residing in apartment complexes; however, few studies have been conducted to determine what these demands entail. This study explores the demands of elderly residents in relation to property management services to bridge the gap between knowledge and practical implementation. This study also examines service demand differences among older residents to help the property management industry provide customized services.

The following section presents information drawn from the existing body of the literature on aging in place, factors that contribute to successfully aging in place, and the service gap in the property management industry. Section 2 presents the questionnaire design and research participants. Section 3 presents the aspects of elderly service demands as identified using factor analysis. Section 4 presents the analyzed results of service demand differences among elderly people by implementing cluster analysis and the chi-square test. Section 5 discusses analysis results. The final section summarizes findings and presents suggestions for further research.

\section{Literature review}

\subsection{Aging in place}

The definition of old age differs among countries. Most developed countries consider the age of 65 years, roughly equivalent to retirement age, as the beginning of old age. Developing countries often define old age, not by years, but by new roles, loss of previous roles, or the inability to make active contributions to society or carry out family roles (Maharaj, 2012). Therefore, some gerontologists have recognized the diversity of old age by defining subgroups, such as "young-old" (65-74 years), "middle-old" (74-84 years), and "oldest-old" (above 85 years) (Zizza, Ellison, \& Wernette, 2009). The definitions of old age continue to change as life expectancy increases owing to technological and medical developments.

According to the Centers for Disease Control and Prevention, U.S. Department of Health \& Human Services (2013), aging in place is "the ability to live in one's own home and community safely, independently, and comfortably, regardless of age, income, or ability level." Aging in place enables elderly people to maintain a level of dignity, independence, and autonomy and maximize self-fulfillment from their preferred lifestyle (Keeling, 1999; Wiles, Leibing, Guberman, Reeve, \& Allen, 2012). Elderly people receive social support by staying connected to family and friends. Aging in place is thus also connected to a person's sense of attachment, security, and familiarity (Wiles et al., 2012). It is preferable for elderly people to remain productive and an integral part of society (Ball, 2004). In addition to the economic cost of moving to institutional care arrangements, such as a nursing home, there are additional negative factors such as low levels of privacy and dignity and the burden of over care (Jayantha, Qian, \& Yi, 2018).

Research conducted in different countries, such as Australia (Judd, Olsberg, Quinn, Groenhart, \& Demirbilek, 2010), Czech (Temelová \& Dvořáková, 2012), Germany (Kramer \& Pfaffenbach, 2011), and the United States (Farber, Shinkle, Lynott, Fox-Grage, \& Harrell, 2011), has shown that it is preferable for elderly people to live in their current residence as long as possible while aging. According to a US survey, $90 \%$ of adults over the age of 65 years reported that they would prefer to stay in their homes (Farber et al., 2011). In Taiwan, $76.31 \%$ of adults between the age of 55 and 64 years and $78.7 \%$ of adults over the age of 65 years would prefer to age in their homes (Ministry of Health and Welfare, 2018). This result echoes the finding of another study that reported that the proportion of older people who prefer to stay in their current residence as they age increases with age (Boldy, Grenade, Lewin, Karol, \& Burton, 2011). A 2014 survey conducted in Taiwan revealed that $60.46 \%$ of adults between the age of 55 and 64 years and $72.95 \%$ of adults over the age of 65 years prefer to age in their homes (Ministry of Health and Welfare, 2014); it also revealed that the intention of elderly people to age in place is now higher than that recorded previously.

Another significant factor influencing the desire of elderly people to age in place is that a majority of older people receive unpaid care from their spouse or adult children (Judd et al., 2010; Pickard, Wittenberg, ComasHerrera, King, \& Malley, 2012). However, the increased mobility of younger generations while seeking employment may present a possible contradiction of this support factor (Keeling, 1999). Considerable uncertainty over the 
supply of unpaid care by their relatives suggests that there is a need to shift from informal to formal care (Pickard, 2015). Ahn, Kwon, and Kang (2017) suggest that comprehensive community-based support and services should be provided to older individuals to promote successful aging in place. Therefore, in order for governments and industries to fulfill this desire of elderly people to successfully age in place, the development of community care and services is essential. Property management companies are often the closest service providers for residents of apartment complexes. Services related to property management are an essential part of assisting elderly individuals to age in their homes.

\subsection{Factors for successful aging in place}

Community engagement, home and community features, and transportation and mobility are all identifiable as key contributors to successful aging in place. These factors help elderly individuals maintain health, safety, independence, and privacy as they age in their homes and communities (Boldy et al., 2011; Farber et al., 2011). Community engagement is defined as "involvement in a range of activities and relationships that link a person with their community, including community attachment, neighboring and informal assistance, organizational memberships, volunteering, charitable giving, and involvement in community affairs, which also encompasses local political participation" (Kochera, Straight, \& Guterbock, 2005). After retirement, an older adult's daily life changes from being focused on work to spending more time on interpersonal relationships, leisure activities, health care, and learning. Some older adults tend to go out and engage in more social activities. Community engagement has the potential to involve older adults in meaningful, defined social roles that contribute to health and well-being in later life (Wong, 2012). Neighborhood assistance is an essential column of support in the daily lives of elderly people, in addition to support from family members or friends (Fischer, 2014). Emotional support contributes to better cognitive function in elderly people (Seeman, Lusignolo, Albert, \& Berkman, 2001). Community participation also helps elderly people develop and maintain social ties and obtain support, which acts as a buffer when they are faced with psychological pressure or setbacks. It satisfies their need to be respected and their desire for intimacy and security, which contributes to the overall physical and mental health of elderly people (Barker, 2013). Community engagement through volunteer activities and helping others provides another important way of attaining self-esteem and a sense of personal control, which generates positive emotions (Ryff \& Singer, 1998).

Home life is a key to personal independence and engagement in community life (Kochera et al., 2005). Most elderly people display high residential stability and feel firmly attached to their home and neighborhood. In addition to the local area and relations with neighbors, residential satisfaction stems from the home itself and access to services (Rioux \& Wemer, 2011). The physical home environment is an important factor. To enable aging in place, the residential environment may need to be rebuilt or maintained, and emergency devices may need to be installed to ensure home and community safety (Boldy et al., 2011). Elderly people's health limitations also increase vulnerability to environmental challenges, which increase the importance of housing and neighborhood (Wahl \& Oswald, 2010). Home and community safety considerations influence not only property values and personal security (Temelová \& Dvořáková, 2012) but also activities that residents are willing to engage in (Kochera et al., 2005).

In addition to the physical environment of home and community, comprehensive support services are necessary to achieve successful aging in place (Ahn et al., 2017; Jayantha et al., 2018). Elderly people may encounter difficulties keeping up with home repairs or maintenance or have trouble finding affordable and trustworthy repair companies (Ormond, Black, Tilly, \& Thomas, 2004; Fischer, 2014). It is also essential to integrate social resources and effectively deliver messages to elderly people within a community. Communication and information sharing among elderly people is important for their daily life (Xia, Zuo, Skitmore, Chen, \& Rarasati, 2015). Receiving informational assistance from neighbors and exchanging useful information with others help strengthen community attachment (Kochera et al., 2005). These supportive services include health care, medical assistance, auxiliary appliance provision, psychological consultation, daycare, food supply, family support, education, legal advice, transportation, recreation, and informational supply (Ministry of Health and Welfare, 2015). Thus, the availability of supportive services in the community influences the quality of life of elderly people and impacts the degree to which they can become involved in activities. A healthy community environment that provides safety, support, and care services directly influences the quality of life of elderly people, increases their attachment to the community, enhances their health status, and is essential to aging in place (Seeman et al., 2001; Frumkin, Frank, \& Jackson, 2004).

Multiple modes of transportation allow elderly individuals to physically reach other people and participate in activities in their community, contributing to their independence and feeling of control over their own lives. Despite the fact that automobiles are the most frequent mode of transportation used by the elderly in rural areas (Fischer, 2014), and that walking and public transport are the most frequently used by those in cities (Temelová \& Dvoŕáková, 2012), reports shows that a majority of trips of elderly people are for daily shopping and socializing as a leisure activity (Temelová \& Dvořáková, 2012; Fischer, 2014). In other words, transportation and mobility is a fundamental need of elderly people in order to be able to access people and activities and to participate the community. Elderly people may experience some form of physical disability, which can lead to functional or mobility limitations (Rioux \& Wemer, 2011). Poor mobility of some seniors may hinder their active participation in the 
community, hamper access to timely health care, or create a need for a personal care assistant (Ormond et al., 2004). Functional or mobility limitations as well as not having anyone to accompany them may result in disabled elderly people not seeking medical care. The policy of having a doctor pay a home visit or the technological application of a remote home care system or other assistive devices might increase accessibility to medical treatment, partially solving issues resulting from poor mobility.

Although governments are committed to policies and services that relate to social involvement, volunteering and community service, land use and zoning configurations, affordable housing, transportation plans, improved driving/travel arrangements, and long-term care systems, which may allow elderly people to successfully age in place, the private sector also has to work together to meet the challenges of an aging society. The property management industry should consider the provision of comprehensive community services to help apartment complexes they serve achieve a suitable aging-in-place environment.

\subsection{Service gap in the property management industry}

To support elderly people who wish to age in place, different industries have proposed various technologies or services to serve people's needs. For example, stair lifts and wheelchairs increase accessibility to existing public areas (Lin \& Bao, 2015); ultrasonic whistles can be used to announce emergency incidents at homes (Biermann, Offermann-van Heek, Himmel, \& Ziefle, 2018); and fall alarm systems and position detection systems can assist in monitoring behaviors (Wang, Zhang, Li, Lee, \& Sherratt, 2014). Various other intelligent/smart home functions using wireless technology can also support home care through medical monitoring and home automation (Memon, Wagner, Pedersen, Beevi, \& Hansen, 2014). Such technical services provide elderly prevention and rehabilitation measures, allowing elderly individuals to live independently for longer, despite physical or mental restriction (Memon et al., 2014; Biermann et al., 2018). Other industries, such as tourism (Kim, Woo, \& Uysal, 2015), clothing (Yin \& Zhou, 2017), furniture (Liu, Zhang, \& Jiang, 2018), and mobility (Wang, Lyu, \& Chen, 2018), have also made efforts to target elder customers and provide suitable services.

When faced with an aging demographic, the research focus of property management is set more on retirement villages and elderly's residential satisfaction. Xia et al. (2015) conducted a case study of a retirement village in Australia to identify sustainability features that attract older people and concluded that environmentally friendly features, such as an eco-friendly design of the site and floor plan, and facility and daily service provision should be incorporated into a village's development for sustainability. S. Liu, Jin, Xie, C. Liu, and Mills (2018) studied the land and financial issues of retirement villages and proposed public-private partnership in the construction of retirement villages to make them more affordable. Te- melová and Dvořáková (2012) evaluated the residential satisfaction of elderly inhabitants in Prague city and suggested that less accessibility to daily facilities, weak certainty of neighbor's social support, and low night-time safety resulted in low residential satisfaction of elderly people. Fernández-Carro, Módenes, and Spijker (2015) conducted a cross-European study of factors that enhance elderly residential satisfaction and found that the accessibility to living space and usability of their dwelling play an important role in residential satisfaction in old age. However, few studies have focused on the service needs of elderly people aging in their homes. Although researches have mentioned the importance of a community's physical environment and support services, the details of service provision required for elderly people living in apartment complexes are still too vague for the property management industry to practically make implementations.

According to the Service Quality Gap Model (Parasuraman, Zeithaml, \& Berry, 1985), to increase customer satisfaction, management companies must try to minimize the gap between customer expectations and management perceptions of these expectations, which arises from the management's lack of understanding of the former. In this paper, the demands of elderly residents regarding property management services are explored to bridge the gap between customer expectation and management implementation. The paper also examines service demand differences among older residents to facilitate improved service provision throughout the property management industry.

\section{Questionnaire development and distribution}

Because no service aspects of property management focusing on elderly residents have been proposed, this study self-developed potential service items to explore elderly people's service demands from the viewpoint of helping them age in their homes. After questionnaire data collection, designed service items will be integrated to service demand aspects through factor analysis for the reference of property management companies. To study the service demands of elderly people and their expectations from the property management company of an apartment complex while they are aging in their homes, potential service items were designed by incorporating concepts mentioned in the previous section, which were found to contribute to successfully aging in place, into practice in property management services. The designed service items covered areas related to community engagement (leisure activities, information sharing, and volunteering), physical home and community environment (environment safety and facility provision), supportive services, and services for mobility. The developed service items were also discussed with property management professionals to ensure the feasibility of providing these services practically, either by the company itself or by cross-industry cooperation.

Initially, 45 service items were designed, as shown in Table 1. Respondents needed to respond to a statement regarding how a service item would help make their life 
Table 1. Initial service items

\begin{tabular}{|c|c|c|}
\hline No. & $\begin{array}{l}\text { Initial } \\
\text { No. }\end{array}$ & Service item \\
\hline S1 & 1 & $\begin{array}{l}\text { To offer health-screening activities in the apartment complex (such as blood pressure and blood glucose } \\
\text { measurement) }\end{array}$ \\
\hline S2 & 2 & To arrange for a medical professional to offer health consultation and personal care \\
\hline S3 & 3 & To provide lectures related to health and medical care in the apartment complex (such as on diet and medication safety) \\
\hline S4 & 4 & To cooperate with nearby hospitals to provide the apartment complex with medical consultation \\
\hline S5 & 5 & To provide information on how to buy a wheelchair or other assistive devices for elderly people \\
\hline S6 & 6 & To set up a psychological counseling office in the apartment complex \\
\hline S7 & 7 & To provide the disabled in the apartment complex with home care services \\
\hline S8 & 8 & To arrange a regular schedule of home visits in the apartment complex \\
\hline S9 & 9 & To provide a nutritional meal to elderly people in the apartment complex \\
\hline S10 & 10 & To assist elderly people in organizing a food delivery service \\
\hline S11 & 11 & To provide pre-need funeral arrangements and related services to elderly people in the apartment complex \\
\hline S12 & 12 & To deliver information regarding government welfare policies to elderly people in the apartment complex \\
\hline S13 & 13 & To provide a shuttle bus service between the apartment complex and the hospital \\
\hline S14 & 14 & To offer a financial planning advisory service in the apartment complex \\
\hline S15 & 15 & To offer information about retirement and career planning in the apartment complex \\
\hline- & 16 & To hold volunteer activities that allow elderly people to volunteer in the community and assist in community affairs \\
\hline S16 & 17 & To provide recreational areas for frequent interaction between neighbors \\
\hline S17 & 18 & To frequently hold various activities to increase neighbor interaction \\
\hline S18 & 19 & To provide employment information for elderly people in the apartment complex \\
\hline S19 & 20 & To provide leisure- and travel-related information in the service center of the apartment complex \\
\hline S20 & 21 & To participate in leisure sports to improve health (such as aerobics, tai chi, and hiking) \\
\hline- & 22 & To have someone teach programs likes gymnastics or yoga in the morning or evening \\
\hline $\mathrm{S} 21$ & 23 & To offer fitness facilities for older people to exercise \\
\hline S22 & 24 & To make travel arrangements to enhance relationships with neighbors through active interaction \\
\hline S23 & 25 & To facilitate the use of amenities in the apartment complex (for playing mahjong, singing, or playing table tennis) \\
\hline $\mathrm{S} 24$ & 26 & To offer classes to enhance knowledge \\
\hline S25 & 27 & To offer a home delivery service and to assist elderly people in purchasing daily necessities \\
\hline S26 & 28 & To offer a laundry service in the apartment complex \\
\hline $\mathrm{S} 27$ & 29 & To offer a housecleaning service in the apartment complex \\
\hline S28 & 30 & $\begin{array}{l}\text { To install an emergency rescue notification system at home (when an emergency occurs, the system can notify the } \\
\text { family member immediately) }\end{array}$ \\
\hline $\mathrm{S} 29$ & 31 & To provide well-trained personnel with emergency rescue expertise \\
\hline $\mathrm{S} 30$ & 32 & To assign personnel to be aware of and check in on elderly households \\
\hline S31 & 33 & To provide personnel to actively care for elderly residents \\
\hline $\mathrm{S} 32$ & 34 & To equip the apartment complex with many emergency buttons (such as the staircase, basement, or roof platform) \\
\hline S33 & 35 & To accompany elderly people when they buy everyday items \\
\hline S34 & 36 & $\begin{array}{l}\text { To remodel the house to ensure the elderly person's safety at home (such as the installation of handrails in the } \\
\text { bathroom, nonslip bars, and nonsliding tiles) }\end{array}$ \\
\hline S35 & 37 & To have someone help aid with administrative matters (such as writing letters, filling out forms, and mailing service) \\
\hline- & 38 & To have someone remind me to take medicine \\
\hline- & 39 & To offer courses that cultivate a hobby of interest (flower arrangement, bread making, crafts, or painting) \\
\hline S36 & 40 & To have someone accompany elderly people to the hospital for medical treatment \\
\hline S37 & 41 & To rebuild public areas in the apartment complex to accommodate elderly people (such as staircase handrails or slopes) \\
\hline S38 & 42 & To facilitate the usage of long-range health-monitoring equipment at home \\
\hline- & 43 & To host religion-related events \\
\hline- & 44 & To hold volunteer activities so elderly people can participate to help people in need \\
\hline- & 45 & To provide a reading room in the community for elderly people to use \\
\hline
\end{tabular}

Note: - indicates that the item was deleted after the pre-test. 
more comfortable once they reach the age of 65 . A fivepoint Likert scale was used, with responses from "totally agree" (five points) to "totally disagree" (one point). To examine the reliability and consistency of the designed items, 50 valid samples were collected for the pre-test. An item analysis was conducted to examine the reliability of self-developed service items. First, an independent sample t-test was used to test the significance of the difference between the average scores of the upper $27 \%$ scorers and lower $27 \%$ scorers in each item to determine item discrimination (Cureton, 1957). Second, Pearson's correlation analysis was used to examine correlations between each item's score and the total score to assess internal construct validity. A correlation coefficient of $\geq 0.4$ was used as the cutoff for adequate correlation (Armor, 1973). After performing t-test and Pearson's correlation analyses, seven service items that were considered indiscriminate were deleted, and the other 38 service items remained, as numbered from S1 to S38 in Table 1. Reliability analysis was performed to measure the reliability and consistency of the remaining service items, and Cronbach's a was 0.941, indicating excellent internal consistency (Nunnally \& Bernstein, 2010).

The formal questionnaire comprised three parts. The first part focuses on demographic data and the living environment information of respondents, the second part queries respondents regarding their willingness to age in place and the reasons why he/she chooses aging in place, and the third part contains the 38 service items mentioned above with statements that they needed to respond to. The questionnaires were distributed to potential retirees over the age of 50 who lived in apartment complexes located in northern and central Taiwan. Five hundred and twenty final questionnaires were delivered, and 411 responses were collected. Among the respondents, 257 were considered to be valid, with a valid return rate of $62.5 \%$.

Table 2 shows respondents' demographic statistics. Among the respondents, 158 were men $(61.48 \%)$ and 99 were women $(38.52 \%)$. Furthermore, $39.30 \%$ of respondents aged between 50 and 54 years, followed by $24.13 \%$ and $20.62 \%$ of respondents who were aged between 55 and 59 and between 60 and 64 years, respectively. The majority (35.80\%) of respondents had a high school education, followed by those with a college education (30.74\%). In total, $78.21 \%$ were married and had a healthy spouse. Most families had 2 or more children (83.66\%), and approximately $40 \%$ of the respondents were retired. Around half of the respondents reported their current physical condition as "above good" (56.03\%), whereas $37.35 \%$ reported it to be normal. Eighty respondents had hypertensive symptoms, and $98.83 \%$ could take care of themselves each day.

Regarding the living arrangements of respondents, $38.52 \%$ lived with only their spouses, and $37.35 \%$ lived with the younger generation. More than half of the respondents (57.59\%) lived in buildings with at least seven floors, and $73.15 \%$ were the owners of the property. Administrative affairs and security of apartment complexes were mostly managed by property management companies, with a ratio of $61.87 \%$ and $64.59 \%$, respectively.
A total of $66.93 \%$ of respondents felt satisfied with their current living situation.

With regard to willingness to age in place, $87.55 \%$ of respondents chose to age in their present domicile. The top three reasons were that they were used to the current living environment, that they had good relationships with their neighbors, and that they were able to live with their children or elderly family members (Table 3 ). Results showed that being familiar with the current living environ-

Table 2. Respondents' demographic statistics

\begin{tabular}{|c|c|c|c|}
\hline Item & Category & Number & $\%$ \\
\hline \multirow[t]{2}{*}{ Gender } & Man & 158 & 61.48 \\
\hline & Woman & 99 & 38.52 \\
\hline \multirow[t]{7}{*}{ Age } & $50-54$ years & 101 & 39.30 \\
\hline & $55-59$ years & 62 & 24.13 \\
\hline & 60-64 years & 53 & 20.62 \\
\hline & $65-69$ years & 22 & 8.56 \\
\hline & $70-74$ years & 7 & 2.72 \\
\hline & $75-79$ years & 8 & 3.11 \\
\hline & 80 years and older & 4 & 1.56 \\
\hline \multirow[t]{4}{*}{ Education } & Elementary school & 37 & 14.40 \\
\hline & Junior high school & 40 & 15.56 \\
\hline & High school & 92 & 35.80 \\
\hline & Collage or above & 88 & 34.24 \\
\hline \multirow[t]{3}{*}{ Marriage } & Married (healthy spouse) & 201 & 78.21 \\
\hline & Married (widowed) & 34 & 13.23 \\
\hline & Single & 22 & 8.56 \\
\hline \multirow{6}{*}{$\begin{array}{l}\text { Number of } \\
\text { children }\end{array}$} & None & 9 & 3.50 \\
\hline & 1 & 33 & 12.84 \\
\hline & 2 & 88 & 34.24 \\
\hline & 3 & 79 & 30.74 \\
\hline & 4 & 26 & 10.12 \\
\hline & Above 5 & 22 & 8.56 \\
\hline \multirow[t]{2}{*}{ Retired } & Yes & 103 & 40.08 \\
\hline & Not yet & 154 & 59.92 \\
\hline
\end{tabular}

Table 3. Reasons to age at home

\begin{tabular}{|l|c|c|}
\hline \multicolumn{1}{|c|}{ Reasons (multi-select) } & $\begin{array}{c}\text { Percentage } \\
\text { (\%) }\end{array}$ & Rank \\
\hline $\begin{array}{l}\text { Used to the current living } \\
\text { environment }\end{array}$ & 66.67 & 1 \\
\hline Good relationships with neighbors & 47.11 & 2 \\
\hline $\begin{array}{l}\text { Able to live with children or elderly } \\
\text { family members }\end{array}$ & 46.22 & 3 \\
\hline Convenient transportation & 43.56 & 4 \\
\hline Near to parks & 38.67 & 5 \\
\hline Convenient to go shopping & 37.78 & 6 \\
\hline Near to hospitals & 36.00 & 7 \\
\hline $\begin{array}{l}\text { Proper management of the } \\
\text { apartment complex }\end{array}$ & 34.22 & 8 \\
\hline Good environmental security & 28.00 & 9 \\
\hline Environment suitable for aging & 24.89 & 10 \\
\hline Do not want to change & 24.44 & 11 \\
\hline Have no extra money to relocate & 20.44 & 12 \\
\hline
\end{tabular}


ment, having a suitable living environment (good housing, efficient management, access to transportation, and medical facilities), and having meaningful attachments (living with family members and a good neighborhood) were the main areas of concern for aging in the current residence. Most of the respondents agreed that they would be willing to pay for customized services (63.03\%).

\section{Factor analysis and labeling}

To integrate service items to easily understand service demand aspects for property management companies' practice, factor analysis is implemented. Factor analysis is an ideal data reduction technique that identifies aspects or factors underlying related variables. It integrates numer- ous variables into an easily understood framework (Stevens, 2009). The Kaiser-Meyer-Olkin (KMO) measurement and Bartlett test of sphericity are used to examine whether variables have common factors and are suitable for factor analysis (Bartlett, 1950). For sample data collected in this study, the value of the KMO measure was 0.947, which exceeds 0.5 , and was therefore deemed highly acceptable (Kaiser, 1974). The value of the Bartlett test of sphericity was 5934.854 with an associated significance level of 0.000 . These results showed that the sample data collected by the study were suitable for factor analysis. All 38 service items were deemed adequate to be incorporated into the factor analysis.

After the factor analysis, one service item (S24: to offer classes to enhance knowledge) was deleted due to double

Table 4. Service demand aspects and elderly service demand ranks

\begin{tabular}{|c|c|c|c|c|c|c|c|c|}
\hline $\begin{array}{l}\text { Service demand aspect } \\
\text { naming }\end{array}$ & $\begin{array}{l}\text { Service } \\
\text { item }\end{array}$ & $\begin{array}{c}\text { Factor } \\
\text { loading }\end{array}$ & Cronbach's $\alpha$ & Mean score & $\begin{array}{l}\text { Standard } \\
\text { deviation }\end{array}$ & Rank & $\begin{array}{c}\text { Aspect } \\
\text { mean score }\end{array}$ & $\begin{array}{c}\text { Aspect } \\
\text { rank }\end{array}$ \\
\hline \multirow{7}{*}{$\begin{array}{l}\text { Factor } 1 \text { (F1): Recreation } \\
\text { and community } \\
\text { participation }\end{array}$} & S22 & 0.834 & \multirow[t]{7}{*}{0.898} & 3.88 & 0.80 & 21 & \multirow[t]{7}{*}{3.897} & \multirow[t]{7}{*}{3} \\
\hline & S20 & 0.773 & & 3.90 & 0.75 & 18 & & \\
\hline & S23 & 0.729 & & 3.80 & 0.92 & 24 & & \\
\hline & S16 & 0.725 & & 3.89 & 0.75 & 20 & & \\
\hline & S21 & 0.634 & & 3.91 & 0.79 & 17 & & \\
\hline & S17 & 0.624 & & 3.96 & 0.68 & 13 & & \\
\hline & S19 & 0.558 & & 3.94 & 0.75 & 15 & & \\
\hline \multirow{5}{*}{$\begin{array}{l}\text { Factor } 2(\mathrm{~F} 2) \text { : } \\
\text { Home and remodeling }\end{array}$} & S35 & 0.906 & \multirow[t]{5}{*}{0.857} & 3.70 & 0.82 & 32 & \multirow[t]{5}{*}{3.830} & \multirow[t]{5}{*}{5} \\
\hline & S36 & 0.783 & & 3.77 & 0.82 & 26 & & \\
\hline & S34 & 0.724 & & 4.03 & 0.78 & 8 & & \\
\hline & S37 & 0.716 & & 3.97 & 0.82 & 12 & & \\
\hline & S38 & 0.704 & & 3.68 & 0.84 & 33 & & \\
\hline \multirow{5}{*}{$\begin{array}{l}\text { Factor } 3(\mathrm{~F} 3) \text { : } \\
\text { Rescue and care }\end{array}$} & S29 & 0.803 & \multirow[t]{5}{*}{0.889} & 4.07 & 0.78 & 3 & \multirow[t]{5}{*}{4.076} & \multirow[t]{5}{*}{1} \\
\hline & S30 & 0.777 & & 4.07 & 0.75 & 4 & & \\
\hline & S31 & 0.747 & & 4.05 & 0.79 & 6 & & \\
\hline & S28 & 0.727 & & 4.13 & 0.82 & 1 & & \\
\hline & S32 & 0.622 & & 4.06 & 0.85 & 5 & & \\
\hline \multirow{5}{*}{$\begin{array}{l}\text { Factor } 4(\mathrm{~F} 4) \text { : } \\
\text { Health and medical } \\
\text { services }\end{array}$} & S3 & 0.847 & \multirow[t]{5}{*}{0.914} & 3.99 & 0.74 & 10 & \multirow[t]{5}{*}{3.984} & \multirow[t]{5}{*}{2} \\
\hline & S4 & 0.817 & & 4.01 & 0.73 & 9 & & \\
\hline & S1 & 0.706 & & 4.09 & 0.73 & 2 & & \\
\hline & S5 & 0.676 & & 3.79 & 0.75 & 25 & & \\
\hline & S2 & 0.663 & & 4.04 & 0.71 & 7 & & \\
\hline \multirow{5}{*}{$\begin{array}{l}\text { Factor } 5 \text { (F5): } \\
\text { Welfare, mobility and } \\
\text { nutrition }\end{array}$} & S12 & 0.830 & \multirow[t]{5}{*}{0.856} & 3.94 & 0.80 & 14 & \multirow[t]{5}{*}{3.838} & \multirow[t]{5}{*}{4} \\
\hline & S9 & 0.629 & & 3.84 & 0.85 & 22 & & \\
\hline & S11 & 0.617 & & 3.54 & 0.84 & 38 & & \\
\hline & S13 & 0.611 & & 3.98 & 0.89 & 11 & & \\
\hline & S10 & 0.583 & & 3.89 & 0.85 & 19 & & \\
\hline \multirow{7}{*}{$\begin{array}{l}\text { Factor } 6(\mathrm{~F} 6) \text { : } \\
\text { Information and home } \\
\text { services }\end{array}$} & S14 & 0.780 & \multirow[t]{7}{*}{0.889} & 3.66 & 0.81 & 34 & \multirow[t]{7}{*}{3.677} & \multirow[t]{7}{*}{7} \\
\hline & S15 & 0.778 & & 3.73 & 0.84 & 29 & & \\
\hline & S25 & 0.656 & & 3.73 & 0.85 & 28 & & \\
\hline & S26 & 0.621 & & 3.63 & 0.86 & 36 & & \\
\hline & S27 & 0.589 & & 3.62 & 0.92 & 37 & & \\
\hline & S18 & 0.436 & & 3.72 & 0.82 & 30 & & \\
\hline & S33 & 0.405 & & 3.65 & 0.87 & 35 & & \\
\hline \multirow{3}{*}{$\begin{array}{l}\text { Factor } 7 \text { (F7): } \\
\text { Accompaniment and } \\
\text { consultation }\end{array}$} & S6 & 0.854 & \multirow[t]{3}{*}{0.825} & 3.72 & 0.80 & 31 & 3.803 & 6 \\
\hline & S7 & 0.766 & & 3.93 & 0.79 & 16 & & \\
\hline & S8 & 0.617 & & 3.76 & 0.86 & 27 & & \\
\hline
\end{tabular}


loading. The remaining 37 service items were extracted with factor loading values exceeding 0.5 via principal component analysis. After factor analysis, seven factors (service demand aspects) with eigenvalues greater than one were extracted as shown in Table 4. No service item was double loaded in any factor. The seven factors explained $68.912 \%$ of the accumulated interpretation variance.

By examining the contents of service items associated with each factor (service demand aspect), each service demand aspect was named accordingly (Table 4). The first service demand aspect, which included seven service items, was named "recreation and community participation," and mainly reflected an elderly person's need for recreation, exercise, and community participation and involved aspects such as tourism, recreation or lounge spaces, and participation in sports. The second aspect, which included five service items, was named "home and remodeling" and mainly concerned the living environment of an elderly person. The third aspect, which included five service items related to emergency services and care of elderly people, was named "rescue and care". The fourth aspect, which included five service items related to health and medical needs, was named "health and medical services". The fifth aspect, which included five service items related to meal and car services, was named "welfare, mobility, and nutrition." The sixth aspect was named "information and home services" and reflected family services and relevant information needed. The last aspect, which included three items related to psychological counseling and companionship, was named "accompaniment and consultation." The Cronbach's $\alpha$ of each service demand aspect was above 0.8 , indicating excellent internal consistency.

Using the average scores of each aspect (Table 4), the areas of greatest concern for elderly people can be ranked in order of importance: "F3: rescue and care," "F4: health and medical services," "F1: recreation and community participation," "F5: welfare, mobility and nutrition," "F2: home and remodeling," "F7: accompaniment and consultation," and "F6: information and home services." The top three service demand items were "S28: to install an emergency rescue notification system at home (when an emergency occurs, the system can notify the family member immediately)," "S1: to offer health-screening activities in the apartment complex (such as blood pressure and blood glucose measurement)," and "S29: to provide well-trained personnel in the apartment complex with emergency rescue expertise." This result shows that elderly people attach a great deal of importance to their safety and health and hope to get immediate aid and assistance when accidents happen. As reported, falls and fall-related injuries are a significant threat to the health, independence, and even the lives of older people. Thus, it is critical to get help quickly after a fall has occurred (Yared \& Abdulrazak, 2016). According to a survey of elderly people in Taiwan, approximately one-third of respondents said that they would not be able to handle it by themselves if they fell and were injured at home, and nearly $10 \%$ said that they would not be able to find help within a short period of time in the case of an emergency (Hsiao, 2007). This finding confirms the importance of installing emergency rescue notification systems as well as ensuring that the emergency response capabilities of the field personnel provided by the property management company are sufficient. The lowest ranked items were "S11: to provide pre-need funeral arrangements and related services to elderly people in the apartment complex," "S27: to offer a housecleaning service in the apartment complex," and "S26: to offer a laundry service in the apartment complex." This result suggests that pre-need funeral arrangements might still be a taboo subject. When elderly people are still able to take care of themselves, taking into account their health conditions, they need few services to manage their daily lives. The scores of all service items ranged from 3.54 to 4.13, showing that there were different levels of high demand for each service.

\section{Service demand differences analysis}

Cluster analysis and a chi-square test were used to analyze service demand differences among older residents. To analyze service demand differences, the first step is to separate respondents according to the high and low demand for each service demand aspect and then study the demographic characteristics and residence conditions of each group to determine the distinguishing features of elderly people with high service demands as a reference for future market segments of the property management business. This study implemented cluster analysis to identify high-demand and low-demand groups for each aspect. Cluster analysis is a classic method used to classify samples in such a way that objects in the same group are more similar to each other than to those in other groups (Kaufman \& Rousseeuw, 2009). The method of k-means clustering, which partitions samples into $k$ clusters in which each sample belongs to the cluster with the nearest mean, was implemented. In this study, k equals 2.

Based on the scores for each aspect, respondents were separated into two groups $(\mathrm{k}=2)$ by using cluster analysis, as shown in Table 5. For each aspect, the group with the higher mean score was labeled "high demand," and the other was labeled "low demand." Taking the F1 aspect as an example, 185 samples were identified as "high demand" and 72 samples as "low demand." The mean scores of these two groups were 4.199 and 3.119, respectively. An independent $t$-test confirmed that these two groups were significantly different from each other ( $t$ value $=20.533$, $\mathrm{p}<0.01$ ). As shown in Table 5, the results of the t-test showed that the two identified groups differed significantly from each other in every aspect.

The chi-square test is commonly used to test relationships between categorical variables; thus, it was used to determine whether the two clusters (high- and low-demand groups) of each aspect showed significant differences in demographic characteristics and residence conditions. As shown in Tables 6 and 7, results indicated that there 
Table 5. Cluster of high- and low-demand groups

\begin{tabular}{|c|c|c|c|c|c|}
\hline Service demand aspect & Cluster & Number & Mean score & Standard deviation & $\mathrm{t}$ value \\
\hline \multirow[t]{2}{*}{ F1 } & High demand & 185 & 4.199 & 0.366 & \multirow[t]{2}{*}{$20.533^{\star *}$} \\
\hline & Low demand & 72 & 3.119 & 0.409 & \\
\hline \multirow[t]{2}{*}{$\mathrm{F} 2$} & High demand & 195 & 4.105 & 0.417 & \multirow[t]{2}{*}{$18.010^{\star *}$} \\
\hline & Low demand & 62 & 2.968 & 0.481 & \\
\hline \multirow[t]{2}{*}{ F3 } & High demand & 220 & 4.287 & 0.447 & \multirow[t]{2}{*}{$17.732^{* *}$} \\
\hline & Low demand & 37 & 2.832 & 0.545 & \\
\hline \multirow[t]{2}{*}{$\mathrm{F} 4$} & High demand & 233 & 4.122 & 0.421 & \multirow[t]{2}{*}{$13.685^{\star x}$} \\
\hline & Low demand & 24 & 2.625 & 0.519 & \\
\hline \multirow[t]{2}{*}{ F5 } & High demand & 188 & 4.156 & 0.422 & \multirow[t]{2}{*}{$18.262^{\star *}$} \\
\hline & Low demand & 69 & 3.003 & 0.501 & \\
\hline \multirow[t]{2}{*}{ F6 } & High demand & 186 & 3.991 & 0.404 & \multirow[t]{2}{*}{$19.330^{\star *}$} \\
\hline & Low demand & 71 & 2.855 & 0.463 & \\
\hline \multirow[t]{2}{*}{ F7 } & High demand & 181 & 4.157 & 0.451 & \multirow[t]{2}{*}{$19.608^{\star x}$} \\
\hline & Low demand & 76 & 2.961 & 0.435 & \\
\hline
\end{tabular}

Note: ${ }^{* *} \mathrm{p}<0.01$.

Table 6. Chi-square test results between demographic characteristics and the demand clusters of each service demand aspect

\begin{tabular}{|l|c|c|c|c|c|c|c|}
\hline Demographic characteristics & F1 & F2 & F3 & F4 & F5 & F6 & F7 \\
\hline Gender & 0.245 & 0.070 & 1.411 & 0.598 & 1.755 & 0.035 & 2.196 \\
\hline Age & 6.636 & 9.481 & 5.410 & 6.857 & 2.918 & 9.500 & 7.463 \\
\hline Education & 4.147 & 9.312 & 1.582 & 6.224 & 4.611 & $11.545^{\star}$ & $10.335^{\star}$ \\
\hline Marriage & 2.112 & 1.708 & 5.001 & $9.387^{\star *}$ & 4.279 & 4.076 & $13.560^{\star \star}$ \\
\hline Number of children & 7.113 & 2.358 & $12.585^{\star}$ & 4.946 & 5.649 & 6.341 & 7.522 \\
\hline Retired & 0.794 & 0.879 & 0.440 & 0.365 & 0.924 & $7.382^{\star}$ & 0.023 \\
\hline Occupation & 8.414 & 5.292 & 7.730 & 9.749 & 9.581 & $17.211^{\star}$ & 2.632 \\
\hline Physical condition & $10.015^{\star}$ & 3.918 & 5.623 & 3.394 & 0.489 & 3.089 & 2.999 \\
\hline Disease & $21.598^{\star}$ & 17.355 & 9.891 & 8.995 & 16.893 & 12.823 & 8.251 \\
\hline Religion & 4.221 & 7.952 & $12.676^{\star}$ & 11.814 & 4.943 & 11.061 & 7.186 \\
\hline
\end{tabular}

Note: ${ }^{* *} \mathrm{p}<0.01 ;{ }^{*} \mathrm{p}<0.05$.

Table 7. Chi-square test results between residence conditions and the demand clusters of each service demand aspect

\begin{tabular}{|l|c|c|c|c|c|c|c|}
\hline \multicolumn{1}{|c|}{ Residence conditions } & F1 & F2 & F3 & F4 & F5 & F6 & F7 \\
\hline $\begin{array}{l}\text { Satisfaction with the } \\
\text { apartment complex condition }\end{array}$ & $19.880^{\star *}$ & $13.469^{\star *}$ & $22.954^{* *}$ & $11.563^{\star}$ & 8.936 & $17.233^{\star}$ & 5.598 \\
\hline Living arrangement & $19.816^{* *}$ & $11.354^{\star}$ & $17.701^{\star *}$ & 8.053 & $20.414^{\star *}$ & 6.551 & $25.817^{\star *}$ \\
\hline Years of residence & 2.269 & $13.730^{\star *}$ & 2.673 & 0.262 & 7.348 & 8.130 & 3.156 \\
\hline Living condition & 0.043 & 0.141 & 0.511 & 0.313 & 1.114 & 1.159 & 1.275 \\
\hline Living floor & 0.901 & 4.275 & 4.846 & 2.742 & 4.203 & 7.083 & 1.650 \\
\hline House ownership & $12.940^{\star}$ & 0.827 & 8.963 & 3.851 & 5.425 & 5.958 & $17.888^{\star *}$ \\
\hline Building type & $7.956^{\star}$ & 1.214 & $11.875^{\star *}$ & $12.652^{\star *}$ & 4.535 & 3.305 & 2.110 \\
\hline Apartment complex scale & 0.407 & 1.120 & 1.904 & 4.215 & 3.063 & 0.960 & 1.705 \\
\hline Choose age in place & 0.733 & 0.015 & 3.334 & 3.824 & 0.361 & 0.833 & 3.528 \\
\hline
\end{tabular}

Note: ${ }^{* *} \mathrm{p}<0.01 ;{ }^{*} \mathrm{p}<0.05$. 
were no significant differences between the high-demand and low-demand groups in terms of gender, age, living conditions, apartment building floor, apartment complex scale, and whether they chose to age in place, but the other demographic characteristics and residence conditions influenced service demand levels to varying degrees in each aspect.

\section{Analysis and discussion}

Satisfaction with an apartment complex's condition and living status, which show influence on 5 out of 7 aspects, might be worth focusing on by property management companies. Elderly people who have higher satisfaction with the apartment complex's condition also have high demands with regard to the services of "F1: recreation and community participation," "F2: home and remodeling," "F3: rescue and care," and "F6: information and home services." Elderly people who have lower satisfaction with the apartment complex's condition show low demand regarding "F4: health and medical services." The survey results show that satisfaction with the apartment complex's condition does not increase the demand for "health and medical services." However, the poor performance of property companies in maintaining the apartment complexes will lead to a decreased demand for "health and medical services." This indicates that property management companies must enhance performance on their current services to increase residents' satisfaction about apartment complex conditions before they further provide custom services to elderly people.

The groups that had high demands with regard to "F1: recreation and community participation," "F2: home and remodeling," "F3: rescue and care," "F5: welfare, mobility and nutrition," and "F7: accompany and consultation" consists of a higher percentage of elderly people who live with the young generation than the low-demand groups. Elderly people might rely on the young generation's care and company. While the young generation needs to go out to work during the day and no one is with elderly individuals, property management companies can provide custom services to assist them in their daily lives.

For F1, the high- and low-demand groups were significantly different from each other in terms of their physical condition, disease, satisfaction with the community, living condition, house ownership, and building type. Elderly people that expressed a high demand for recreation and community participation services were generally healthier than those in the low-demand group. Of those in the high-demand group, $51.35 \%$ felt that they were in good physical condition and $43.24 \%$ said they had no diseases, whereas in the low-demand group, the values were $37.5 \%$ and $27.78 \%$, respectively. Those in the high-demand group were also more satisfied with the conditions of apartment complexes ( $74.60 \%$ vs. $47.22 \%$ in the low-demand group), and a higher percentage of them lived with the younger generation ( $43.78 \%$ vs. $20.83 \%$ ). However, for older adults staying with their friends or in a townhouse, the demand for recreation and community participation services was relatively lower compared with others.

For F2, the high- and low-demand groups were significantly different from each other with regard to satisfaction with conditions of the apartment complex, living arrangements, and years of residence. Older adults with a high demand for home and remodeling services were more satisfied with the conditions of apartment complexes $(16.41 \%$ were strongly satisfied vs. only $4.84 \%$ in the low-demand group), and a higher percentage of them lived with the younger generation $(41.03 \%$ vs. $25.81 \%$ in the low-demand group). The percentage of those who had spent 16 to 20 years in the same place of residence was significantly higher in the high-demand group (18.97\%) than those in the low-demand group (6.45\%). This result suggests that property management companies should consider providing home and remodeling services, especially to those who live in older apartment complexes.

For F3, the high- and low-demand groups were significantly different from each other with regard to the number of children, religion, satisfaction with the conditions of the apartment complex, living arrangements, and type of building. Elderly people who had more children (3 or above) had a higher demand for rescue and care services than those with fewer children. This result may be due to the fact that some older adults spent their younger days taking care of their children or were full-time parents; as they got older, they were not used to being on their own and needed more care while their children were away from home or if they lived alone. The percentage of those in the high-demand group who lived in buildings with more than seven floors was significantly higher than those of the low-demand group (60.91\% vs. $37.84 \%)$. Living in a high-rise residential building may lead to feelings of alienation due to a lack of interpersonal interaction and meaningful human relationships. In addition, the percentage of respondents who identified as Christians in the lowdemand group (18.92\%) was significantly higher than that in the high-demand group (7.27\%). This may be because Christians have more opportunities to interact with each other by going to worship services and church functions regularly, thereby reducing their demand for this service.

For F4, the high- and low-demand groups were significantly different from each other with regard to marital status, satisfaction with the condition of the apartment complex, and the type of building. The percentage of those who were married and had a healthy spouse in the high-demand group (80.68\%) was significantly higher than that in the low-demand group (54.17\%). This shows that single people or married widows (another type of single) were less concerned with health and medical services. The percentage of high-demand groups living in buildings that had more than seven floors $(60.52 \%)$ was also significantly higher than that of low-demand groups (29.17\%). Property management companies should therefore consider providing elderly residents with health and medical services when apartment complexes are high-rise buildings. 
For F5, the high- and low-demand groups were significantly different from each other with regard to current living arrangements. The percentage of elderly people living with younger generations was significantly higher in the high-demand group (43.09\%) than in the low-demand group $(21.74 \%)$. Property management companies could provide meal services or a food delivery service for elderly people, help arrange for shuttle buses to hospitals, or provide elderly people with relevant information while members of the younger generation are at work.

For F6, the high- and low-demand groups were significantly different from each other with regard to education, retirement status, type of job, and satisfaction with the apartment complex condition. The percentage of elderly people with high school education in the high-demand group $(39.78 \%)$ was significantly higher than that in the low-demand group (25.35\%). The percentage of those who had not yet retired in the high-demand group (65.05\%) was significantly higher than that in the low-demand group $(46.48 \%)$. The percentage of those in the service industries in the high-demand group (50.54\%) was significantly higher than that in the low-demand group $(29.58 \%)$. These results show how education and work status can play a role in the demands of elderly people with regard to information acquisition and home services. Property management companies might consider providing information and home services to elderly people with a high school education or to those who are still working, particularly those in service industries.

For F7, the high- and low-demand groups were significantly different from each other with regard to education level, marital status, living arrangements, and home ownership. The percentage of elderly people with high school education in the high-demand group (40.33\%) was significantly higher than that in the low-demand group (25\%). The percentage of those living with the younger generation

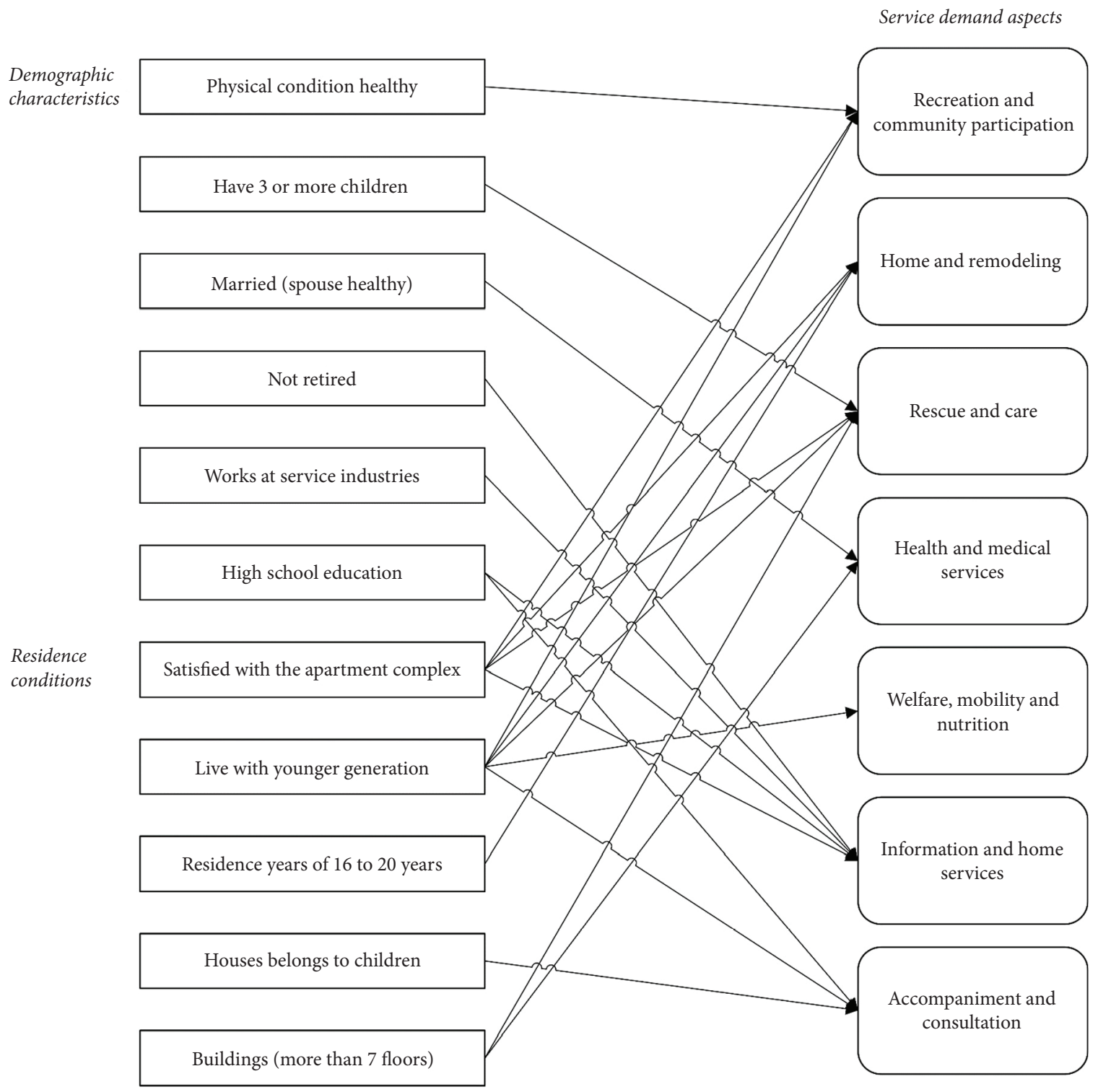

Figure 1. Associations between characteristics and higher service demand aspects 
in the high-demand group (45.30\%) was significantly higher than that in the low-demand group (18.42\%). The percentage of elderly people that lived in a house belonging to their children in the high-demand group (16.02\%) was significantly higher than that in the low-demand group (6.58\%). These results show that older adults who have a high school education or do not own their own houses were less secure about their aging lives and needed accompaniment and to be provided with consultations to help alleviate their fears. In addition, the percentage of single older adults in the low-demand group $(18.42 \%)$ was significantly higher than that in the high-demand group $(4.42 \%)$. A reason for this may be that single people are often more accustomed to the daily patterns of their lives and are thus less likely to need someone to accompany them or provide consultation as they age.

Figure 1 provides a clear summary of demand differences and shows the impact of demographic characteristics and residence conditions on service demands. Property management companies should take into account the characteristics of the residents of apartment complexes they serve in order to supply new services to elderly people that not only provide business opportunities but help implement their corporate social responsibilities.

\section{Conclusions}

This study developed a service demand questionnaire combining the demands of elderly people and services that property management companies could provide in apartment complexes to explore the property management service needs of elderly people to successfully age in place. Responses obtained from the questionnaires showed that the majority of elderly people would prefer to age in place. Factors that played a primary role in the decision of whether to age in place were mostly linked to the living environment and attachments with family members or neighbors.

Most of the respondents reported that they would be willing to pay for customized services. This study identified seven service demand aspects and rated them according to their level of demand, namely "rescue and care," "health and medical services," "recreation and community participation," "welfare, mobility, and nutrition," "home and remodeling," "accompaniment and consultation," and "information and home services." Older people attach great importance to safety and health in their later years and hope to receive care and attention. The average values of service demand aspects were all above 3.6, indicating that respondents as a whole agreed that services would help them age more comfortably.

For satisfying elderly people's "rescue and care" demands, property management companies should provide services such as emergency rescue notification systems in the home or equip the apartment complex with emergency buttons at the staircase, basement, or roof platform to improve community responses and ensure timely help if an emergency occurs. Providing well-trained personnel with emergency rescue expertise, assigning personnel to be aware of elderly households, and providing personnel to care for elderly residents actively are also important.

Property management companies can cooperate with nearby hospitals to offer health-screening activities, health consultations, personal care, or medical consultations and provide health and medical lectures to satisfy the demand for "health and medical services." Remodeling houses to include handrails in the bathroom, nonslip bars, or nonsliding tiles will further ensure safety at home. For public areas, handrails or disabled access slopes are also in high demand.

Holding regular activities to increase neighbor interaction and provision of leisure and travel-related information in the service center of the apartment complex can also satisfy the demand for recreation while enhancing community engagement. Other notable quality-of-life improvements revealed by the survey are the provision of shuttle bus services, information regarding government welfare policies, and a home care service for disabled people. A home delivery service and assistance with purchasing daily necessities are also appropriate services that would satisfy demands, leading to successful aging in place.

The characteristics of the high and low demands of each service aspect were analyzed. Specific characteristics of elderly people, such as the condition of their health, the number of children they had, their marital status, employment status, education level, whether they lived with members of the younger generation, how long they had lived in the same place of residence, and whether they lived in a high-rise building, tended to affect demands they placed on various service aspects. Property management companies should study the declared preferences of elderly residents that they serve in order to better meet their needs.

This study explores the service demand aspects of elderly people for property management companies and examines service demand differences among them. The findings can help property management businesses to understand the needs of elderly customers and minimize the knowledge/provision gap between customer expectations and management perceptions of these expectations. By providing custom-designed services, property management companies can not only satisfy elderly customers' demands but also take corporate social responsibilities to a higher level. The study also revealed that in order to satisfy the needs of elderly people, property management companies might need to consider cross-industry cooperation to provide technical services or professional health/ medical care. As care and services for elderly people are specifically related to communication, privacy, personal identity, and feelings of vulnerability (Woolhead, Calnan, Dieppe, \& Tadd, 2004), field service personnel also need specific training and education to serve residents more effectively. Training programs for field service personnel, as well as the company business strategy, should consider these adjustments early in order to prepare for upcoming changes in an aging society. It is important to note that 
the current service performance of a property management company was a main factor in determining the demands of elderly people for custom-designed services. It is important for property management companies to first perform their current daily services well before proposing further customized services for elderly people. There may be noticeable service demand differences between elderly people in urban and rural areas, as well as between those in different regions and countries. Additional studies should consider analyzing these differences to understand customer demands better.

\section{Acknowledgements}

The authors would like to thank the editor and the anonymous reviewers for their valuable comments and suggestions to improve the quality of the paper.

\section{Author contributions}

Y. H. Huang and P. C. Lee conceived the study and were responsible for the design and development of the data analysis. P. C. Lee was responsible for data collection and analysis. Y. H. Huang and P. C. Lee were responsible for data interpretation. Y. H. Huang wrote the first draft of the manuscript and is responsible for responding to reviewers' comments.

\section{Disclosure statement}

The authors declare no competing financial, professional, or personal interests.

\section{References}

Ahn, M., Kwon, H. J., \& Kang, J. (2017). Supporting aging-in-place well: findings from a cluster analysis of the reasons for agingin-place and perceptions of well-being. Journal of Applied Gerontology, 1-27. https://doi.org/10.1177/0733464817748779

Armor, D. J. (1973). Theta reliability and factor scaling. Sociological Methodology, 5, 17-50. https://doi.org/10.2307/270831

Barker, R. L. (2013). The social work dictionary (6th ed.). Washington: National Association of Social Workers.

Ball, M. S. (2004). Aging in place: a toolkit for local governments. Atlanta Regional Commission, Atlanta.

Bartlett, M. (1950). Tests of significance in factor analysis. British Journal of Psychology, 3, 77-85. https://doi.org/10.1111/j.2044-8317.1950.tb00285.x

Biermann, H., Offermann-van Heek, J., Himmel, S., \& Ziefle, M. (2018). Ambient assisted living as support for aging in place: quantitative users' acceptance study on ultrasonic whistles. JMIR Aging, 1(2), e11825. https://doi.org/10.2196/11825

Boldy, D., Grenade, L., Lewin, G., Karol, E., \& Burton, E. (2011). Older people's decision regarding 'ageing in place': a western Australian case study. Australasian Journal on Ageing, 30(3), 136-142. https://doi.org/10.1111/j.1741-6612.2010.00469.x

Centers for Disease Control and Prevention. (2013). Healthy places terminology: aging in place. Centers for Disease Control and Prevention, Atlanta, GA. Retrieved from http://www.cdc. gov/healthyplaces/terminology.htm
Council for Economic Planning and Development. (2004). Development program and action of service industries. Council for Economic Planning and Development, Executive Yuan, R.O.C. (Taiwan).

Cureton, E. E. (1957). The upper and lower twenty-seven percent rule. Psychometrika, 22, 293-296. https://doi.org/10.1007/ BF02289130

Farber, N., Shinkle, D., Lynott, J., Fox-Grage, W., \& Harrell, R. (2011). Aging in place: a state survey of livability policies and practices. Public Policy Institute, Washington, D.C.

Fernández-Carro, C., Módenes, J. A., \& Spijker, J. (2015). Living conditions as predictor of elderly residential satisfaction. A crossEuropean view by poverty status. European Journal of Ageing, 12(3), 187-202. https://doi.org/10.1007/s10433-015-0338-z

Fischer, T. (2014). Aging population in change-a crucial challenge for structurally weak rural areas in Austria. European Countryside, 6(1), 9-17. https://doi.org/10.2478/euco-2014-0002

Frumkin, H., Frank, L., \& Jackson, R. (2004). Urban sprawl and public health. Washington, DC: Island Press.

Hsiao, H. W. (2007). Senior citizens' needs for elder housing in Taiwan (MS thesis). Department of Social Work, National Taiwan University (in Chinese).

Jayantha, W. M., Qian, Q. K., \& Yi, C. O. (2018). Applicability of 'Aging in Place' in redeveloped public rental housing estates in Hong Kong. Cities, 83, 140-151. https://doi.org/10.1016/j.cities.2018.06.016

Judd, B., Olsberg, D., Quinn, J., Groenhart, L., \& Demirbilek, O. (2010). Dwelling, land and neighbourhood use by older home owners (AHURI final report No. 144). Melbourne, Australia: Australian Housing and Urban Research Institute.

Kaiser, H. F. (1974). An index of factorial simplicity. Psychometrika, 39(1), 31-36. https://doi.org/10.1007/BF02291575

Kaufman, L., \& Rousseeuw, P. J. (2009). Finding groups in data: an introduction to cluster analysis. John Wiley \& Sons.

Keeling, S. (1999). Ageing in (a New Zealand) place: ethnography, policy and practice. Social Policy Journal of New Zealand, 13, 95-114.

Kim, H., Woo, E., \& Uysal, M. (2015). Tourism experience and quality of life among elderly tourists. Tourism Management, 46, 465-476. https://doi.org/10.1016/j.tourman.2014.08.002

Kochera, A., Straight, A., \& Guterbock, T. (2005). Beyond 50.05: a report to the nation on livable communities: creating environments for successful aging. Retrieved from https://assets.aarp. org/rgcenter/il/beyond_50_communities.pdf

Kramer, C., \& Pfaffenbach, C. (2011). Junge alte als neue "Urbaniten"? Mobilitätstrends der generation 50plus. Raumforschung und Raumordnung, 69(2), 79-90. https://doi.org/10.1007/s13147-011-0078-2

Lin, Y., \& Bao, L. (2015). "Wheelchair slow transit" system-based elderly auxiliary travel mode. Frontiers of Architectural Research, 4(3), 220-229. https://doi.org/10.1016/j.foar.2015.06.003

Liu, S. F., Zhang, Y., \& Jiang, M. (2018). ANP-based analysis of design strategy, customer demand, and firm performance of the elderly motorized mobility scooter. Journal of Interdisciplinary Mathematics, 21(2), 431-437. https://doi.org/10.1080/09720502.2017.1420572

Liu, S., Jin, H., Xie, B., Liu, C., \& Mills, A. (2018). Concession period determination for PPP retirement village. International Journal of Strategic Property Management, 22(5), 424-435. https://doi.org/10.3846/ijspm.2018.5476

Maharaj, P. (Ed.). (2012). Aging and health in Africa. Springer Science \& Business Media.

Memon, M., Wagner, S. R., Pedersen, C. F., Beevi, F. H., \& Hansen, F. O. (2014). Ambient assisted living healthcare 
frameworks, platforms, standards, and quality attributes. Sensors, 14(3), 4312-4341. https://doi.org/10.3390/s140304312

Ministry of Health and Welfare. (2014). Report of the senior citizen condition survey 2013. Ministry of Ministry of Health and Welfare, R.O.C. (Taiwan) (in Chinese).

Ministry of Health and Welfare. (2015). Senior citizens welfare act. Ministry of Ministry of Health and Welfare, R.O.C. (Taiwan) (in Chinese).

Ministry of Health and Welfare. (2018). Report of the senior citizen condition survey 2017. Ministry of Ministry of Health and Welfare, R.O.C. (Taiwan) (in Chinese).

Ministry of the Interior. (2015). Report on the housing status survey. Ministry of Interior, R.O.C. (Taiwan) (in Chinese).

National Development Council. (2018). Population projections for the R.O.C. (Taiwan): 2018 2065. National Development Council, R.O.C. (Taiwan).

Nunnally, J. C., \& Bernstein, I. H. (2010). Psychometric theory (3rd ed.). New York: McGraw Hill.

Ormond, B. A., Black, K. J., Tilly, J., \& Thomas, S. (2004). Supportive services programs in naturally occurring retirement communities. Washington: U.S. Department of Health and Human Services.

Parasuraman, A., Zeithaml, V. A., \& Berry, L. L. (1985). A conceptual model of service quality and its implications for future research. Journal of Marketing, 49, 41-50. https://doi.org/10.1177/002224298504900403

Pickard, L., Wittenberg, R., Comas-Herrera, A., King, D., \& Malley, J. (2012). Mapping the future of family care: receipt of informal care by older people with disabilities in England to 2032. Social Policy and Society, 11(4), 533-545. https://doi.org/10.1017/S1474746412000346

Pickard, L. (2015). A growing care gap? The supply of unpaid care for older people by their adult children in England to 2032. Ageing \& Society, 35(1), 96-123. https://doi.org/10.1017/S0144686X13000512

Rioux, L., \& Wemer, C. (2011). Residential satisfaction among aging people living in place. Journal of Environmental Psychology, 31(2), 158-169. https://doi.org/10.1016/j.jenvp.2010.12.001

Ryff, C. D., \& Singer, B. (1998). Middle age and well-being. In H. S. Friedman (Ed.), Encyclopedia of mental health (pp. 707719). San Diego: Academic Press.

Seeman, T., Lusignolo, T., Albert, M., \& Berkman, L. (2001). Social relationships, social support, and patterns of cognitive aging in healthy, high-functioning older adults: MacArthur studies of successful aging. Health Psychology, 20(4), 243-255. https://doi.org/10.1037/0278-6133.20.4.243

Stevens, J., (2009). Applied multivariate statistics for the social science (5th ed.). NY: Routledge.
Temelová, J., \& Dvořáková, N. (2012). Residential satisfaction of elderly in the city centre: the case of revitalizing neighbourhoods in Prague. Cities, 29(5), 310-317.

https://doi.org/10.1016/j.cities.2011.11.015

Wahl, H. W., \& Oswald, F. (2010). Environmental perspectives on aging. In D. Dannefer \& C. Phillipson (Eds.), International handbook of social gerontology (pp. 111-124). London, UK: Sage. https://doi.org/10.4135/9781446200933.n8

Wang, J., Zhang, Z., Li, B., Lee, S., \& Sherratt, R. S. (2014). An enhanced fall detection system for elderly person monitoring using consumer home networks. IEEE Transactions on Consumer Electronics, 60(1), 23-29. https://doi.org/10.1109/TCE.2014.6780921

Wang, L., Lyu, J., \& Chen, M. (2018). Study and practice on seat products design for elderly people. In IOP conference series: materials science and engineering. IOP Publishing. https://doi.org/10.1088/1757-899X/394/3/032130

Wiles, J. L., Leibing, A., Guberman, N., Reeve, J., \& Allen, R. E. S. (2012). The meaning of "aging in place" to older people. Gerontologist, 52(3), 357-366. https://doi.org/10.1093/geront/gnr098

Wong, P. T. (2012). The human quest for meaning: theories, research, and applications (2nd ed.). New York, NJ: Routledge. https://doi.org/10.4324/9780203146286

Woolhead, G., Calnan, M., Dieppe, P., \& Tadd, W. (2004). Dignity in older age: what do older people in the United Kingdom think? Age Ageing, 33(2), 165-170. https://doi.org/10.1093/ageing/afh045

Xia, B., Zuo, J., Skitmore, M., Chen, Q., \& Rarasati, A. (2015). Sustainable retirement village for older people: a case study in Brisbane, Australia. International Journal of Strategic Property Management, 19(2), 149-158. https://doi.org/10.3846/1648715X.2015.1029564

Yared, R., \& Abdulrazak, B. (2016). Ambient technology to assist elderly people in indoor risks. Computers, 5(4), 1-33. https://doi.org/10.3390/computers5040022

Yin, J., \& Zhou, D. (2017, June). An analysis of the dressing features of elderly women in contemporary cities of Hubei province. Paper presented at the $2^{\text {nd }}$ International Conference on Education, Sports, Arts and Management Engineering (ICESAME 2017). https://doi.org/10.2991/icesame-17.2017.414

Zizza, C. A., Ellison, K. J., \& Wernette, C. M. (2009). Total water intakes of community-living middle-old and oldest-old adults. Journals of Gerontology Series A: Biomedical Sciences and Medical Sciences, 64(4), 481-486. https://doi.org/10.1093/gerona/gln045 